\title{
CONTROLLED DELIVERY OF ANTIRETROVIRAL DRUG-LOADED CROSS-LINKED MICROSPHERES BY IONIC GELATION METHOD
}

\author{
PRINCELY $\mathbf{S}^{1 *}$, SALEEM BASHA ${ }^{2}$, NANDHAKUMAR $\mathbf{S}^{1}$, DHANARAJU MD ${ }^{1}$
}

\begin{abstract}
${ }^{1}$ Department of Pharmaceutical Biotechnology, GIET School of Pharmacy, Rajahmundry, Andhra Pradesh, India. ${ }^{2}$ Department of Pharmaceutical Biotechnology, School of Pharmacy, Asmara College of Health Sciences, Asmara, Eritrea, Northeast Africa. Email: sprincelympharm@gmail.com
\end{abstract}

Received: 23 June 2016, Revised and Accepted: 12 July 2016

\section{ABSTRACT}

Objective: Lamivudine (LVD) is a nucleoside reverse transcriptase inhibitor originally developed as an antiretroviral drug and primarily used in the treatment of most common chronic disease of the planet, acquired immune deficiency syndrome and hepatitis B. The main objective of the study is to develop controlled drug delivery system to increase the efficacy of antiretroviral drug, LVD against human immunodeficiency virus infections.

Methods: The microencapsulation of LVD in gelatin microspheres was carried out by cross-linking process with glutaraldehyde saturated toluene using ionic-gelation method. The prepared microspheres were evaluated for particle size analysis, \% yield value, \% drug content, drug entrapment efficiency, scanning electron microscopy for surface morphology, swelling index, accelerated stability studies, Fourier transform infrared radiation spectroscopy (FT-IR) and differential scanning calorimetry (DSC) for polymer drug compatibility, in vitro dissolution efficiency and release kinetic studies.

Results: The obtained microspheres showed very smooth surface and exhibited regular spherical geometry due to higher crosslinking density. FT-IR and DSC revealed the absence of drug polymer interactions. The percentage yield, entrapment efficiency and drug content for F6 LVD microspheres was found to be $79.31 \%, 65.55 \%$ and $96.25 \%$ respectively. The particle size was ranged from $34.61 \%$ to $51.45 \mu$ m sizes and in vitro release profile showed that cross-linking density of gelatin microspheres effectively controlled the release of LVD.

Conclusion: The findings of our investigation demonstrated that F6 of gelatin-LVD microspheres had good controlled release profile with maximum entrapment efficiency and prolonged drug release for $24 \mathrm{hrs}$ or longer and this formulation would be capable of overcoming the drawbacks and limitations of LVD conventional dosage forms.

Keywords: Lamivudine, Microspheres, Controlled release, Gelatin, Fourier transform infrared, Differential scanning calorimetry, In vitro release kinetics.

(C) 2016 The Authors. Published by Innovare Academic Sciences Pvt Ltd. This is an open access article under the CC BY license (http://creativecommons org/licenses/by/4. 0/) DOI: http://dx.doi.org/10.22159/ajpcr.2016.v9i5.13653

\section{INTRODUCTION}

Human immunodeficiency virus (HIV) infection and acquired immune deficiency syndrome (AIDS) constitute one of the most serious infectious diseases challenges to public health globally. AIDS is considered to be an epidemic according to estimates from the UNAIDS/ World Health Organization (WHO) AIDS epidemic update, July 2008. Combating it is one of the eight Millennium Development Goals and a top priority in bilateral and multilateral development aid. The WHO estimated that HIV/AIDS caused $2 \%$ of all deaths and $6 \%$ of deaths due to infectious diseases in India in 1998. If this status continues by 2033 AIDS will account for an estimated $17 \%$ of all deaths and $40 \%$ of deaths from infectious disease [1-3].

Lamivudine is a nucleoside reverse transcriptase inhibitor originally developed as an antiretroviral (ARV) drug and primarily used in the treatment of most common chronic disease of the planet, AIDS, and Hepatitis B. It is an analog of cytidine. It can inhibit both Types (1 and 2) of $\mathrm{HIV}$ reverse transcriptase and also the reverse transcriptase of Hepatitis B. It is phosphorylated to active metabolites that compete for incorporation into viral DNA and act as a chain terminator of DNA synthesis, and therefore, the viral DNA growth is terminated. Lamivudine triphosphate does not interfere with normal cellular DNA metabolism [4-6].

The daily dose of lamivudine is $150 \mathrm{mg}$ twice a day or $300 \mathrm{mg}$ once a day and is rapidly absorbed after oral administration with an absolute bioavailability of $86 \pm 16 \%$, peak serum concentration (Cmax) of $1.5 \pm 0.5 \mathrm{mcg} / \mathrm{ml}$, and mean elimination half-life $(\mathrm{t} 1 / 2)$ of $5-7 \mathrm{hrs}$, thus necessitating frequent administration to maintain constant therapeutic drug levels which may result in poor efficacy of the treatment and low compliance among HIV/AIDS patients. However, the patient receiving lamivudine frequently develop various side effects, i.e., in GPRA-induced thrombocytopenia as well as in central nervous system (CNS), which includes thrombocytopenia, paresthesias, anorexia, nausea, abdominal cramps, depressive disorders, cough, and skin rashes [2]. Moreover, HIV is localized in certain inaccessible compartments of the body such as the CNS, the lymphatic system, and within the macrophages. Currently, available marketed dosage forms of lamivudine do not deliver drugs specific to lymph and only low concentration of drug reaches in the lymphatic system and also cannot be maintained for the necessary duration at the site of HIV localization that leads to the development of multidrug-resistance against the ARV drugs $[7,8]$.

Strategies currently being investigated to overcome these limitations include the identification of new and chemical modification of existing chemical entities, as well as the design and development of novel drug delivery systems. There are growing interests in developing delivery systems for drug targeting to specific sites because of the lack of other effective and practical pharmacological approaches. The optimum effect of many medical treatments is obtained by maintaining the drug concentration in the therapeutic range over a sustained period. This is especially true for highly potent drugs, such as antiviral drugs [9].

The development of controlled release of lamivudine would be beneficial in comparison with the current dose regimens. The basic rationale of controlled drug delivery system is to optimize the biopharmaceutics, pharmacokinetics, and pharmacodynamics properties of a drug in such a way that its utility is maximized through reduction in side 
effects and cure or control the conditions in the shortest possible time using smallest quantity of drug administered by most suitable route. Several delivery systems of lamivudine have been proposed to improve its efficacy and half-life. Among these systems, microparticles may represent a promising alternative as they can facilitate controlled delivery by non-invasive routes such as oral and nasal and also possess many advantages such as high bioavailability, rapid kinetic of absorption as well as avoidance of hepatic first pass effect and improvement of patient compliance [10-16].

Only a limited study lamivudine extended release formulations has been carried out using gelatin. Hence, the objective of the present study includes: (a) Formulation of a sustained release matrix microsphere system containing lamivudine using Gelatin; (b) evaluation of microspheres for various physical characteristics such as drug content, drug entrapment efficiency (DEE), scanning electron microscopy (SEM), swelling index, accelerated stability studies, Fourier transforminfrared (FT-IR) and differential scanning calorimetry (DSC), in vitro drug release, and (c) to fit the drug release data to various drug release models. So, by developing drug-loaded microspheres which will be up-taken by the gut-associated lymphoid tissues can thus result in enhanced drug concentrations in lymphatics, would be capable of reducing the frequency of administration and the dose-dependent side effects associated with the repeated administration of conventional lamivudine tablets. The rationale of this investigation is to develop effective controlled release gelatin lamivudine formulations to overcome the drawbacks and limitations of lamivudine conventional dosage forms.

\section{MATERIALS AND METHODS}

\section{Materials}

Lamivudine was obtained from Glaxo Smith Kline Ltd., Mumbai, India. Gelatin was purchased from Virat Lab, Hyderabad. Acetone, Dichloromethane, and Toluene were obtained from Molychem, Mumbai. Glutaraldehyde and light liquid paraffin were purchased from SD Fine Chemicals Limited, Mumbai and Samir Tech Chemicals, Vadodara. Span 80 was obtained from Oxford Laboratory, Mumbai, and all other chemicals used were of pure and analytical grade.

\section{Methods}

\section{Preparation of lamivudine microspheres [14,17,22]}

Emulsion cross-linking method: Gelatin microspheres were prepared by emulsification method using an overhead stirrer with a threeblade paddle. The drug was dissolved in $10 \mathrm{ml}$ of gelatin solution $(5 \% \mathrm{w} / \mathrm{v})$ which was preheated to $80^{\circ} \mathrm{C}$ and added drop-wise to $30 \mathrm{ml}$ of light liquid paraffin oil containing $1 \% \mathrm{w} / \mathrm{v}$ Span 80 surfactant (with respect to the mass of the oil phase), then the mixture was stirred at $3500 \mathrm{rpm}$ for 10 minutes under turbulent flow conditions to form w/o emulsions. Glutaraldehyde saturated toluene solution was added to the $\mathrm{w} / \mathrm{o}$ emulsion to stabilize the particles. The above mixture was kept at $1000 \mathrm{rpm}$ and to this $1 \mathrm{ml}$ of aqueous glutaraldehyde was added and kept 3 hrs in magnetic stirrer for cross-linking. Microspheres formed were separated by filtration and then washed and dehydrated with $20 \mathrm{ml}$ of acetone. Finally, microspheres were allowed to dry at room temperature $\left(25^{\circ} \mathrm{C}\right)$. Upon drying a yellow to yellowish orange-colored free flowing, fine powder was obtained. Three different formulations of lamivudine-loaded gelatin microspheres using surfactants were prepared by the above-mentioned method. In this study, a total of nine formulations were prepared using liver venous deprivation (LVD): Gelatin: Glutaraldehyde; and labeled as F1 (1:1:2), F2 (1:1:4), F3 (1:1:6), F4 (1:2:2), F5 (1:2:4), F6 (1:2:6), F7 (1:3:2), F8 (1:3:4), and F9 $(1: 3: 6)$.

\section{Evaluation of lamivudine microspheres}

a. Particle size analysis by optical microscopy $[14,19,23]$

The size of the prepared microspheres was measured by the optical microscopy method using a precalibrated ocular and stage micrometer. The instrument was calibrated at 1 unit of eyepiece micrometer which was equal to $1 / 30 \mathrm{~mm}(33.33 \mu \mathrm{m})$. In all measurements, at least 20 particles in five different fields were studied. Particle size was calculated using the following equation.

$$
\mathrm{Xg}=10 \times[(\mathrm{ni} \times \log \mathrm{xi}) / \mathrm{N}]
$$

Where, $\mathrm{Xg}$ is geometric mean diameter, ni is number of particle in range, $\mathrm{xi}$ is the midpoint of the range, and $\mathrm{N}$ is the total number of particles. All the experimental units were analyzed in triplicate $(n=3)$.

b. Percentage yield value of microspheres [26]

The microspheres were evaluated for percentage yield, and the yield was calculated as,

$$
\text { Percentage yield }=\frac{\text { Weight of microsphere recovered }}{\text { Weight }(\text { drug }+ \text { polymer })} \times 100
$$

Results were based on the triplicate determination.

c. Determination of drug content [25]

Drug-loaded microspheres (100 $\mathrm{mg}$ ) were powdered and suspended in $100 \mathrm{ml}$ solution of methanol:Water $(1: 99 \mathrm{v} / \mathrm{v})$. The resultant dispersion was kept for 20 minutes for complete mixing with continuous agitation and filtered through a $0.45 \mu \mathrm{m}$ membrane filter. The drug content was determined spectrophotometrically at $267 \mathrm{~nm}$ using a regression equation derived from the standard graph.

$$
\text { Drug content }=\frac{\text { Sample absorbance }}{\text { Standard absorbance }} \times 100
$$

Results were based on the triplicate determination.

d. DEE [26]

DEE was determined by ultraviolet (UV) spectrophotometric method. The drug was extracted from the microspheres using $1 \mathrm{~N}$ $\mathrm{HCl}$, and the absorbance was measured using UV-Visible (UV-VIS) spectrophotometer at $267 \mathrm{~nm}$. The DEE was calculated by the equation,

$$
\mathrm{DEE}=(\mathrm{Pc} / \mathrm{Tc}) \times 100
$$

Where, Pc is practical content, Tc is the theoretical content. All the formulations were analyzed in triplicate $(\mathrm{n}=3)$.

e. Swelling index [27]

Swelling index was done for measuring the extent of swelling of microspheres in $0.1 \mathrm{~N} \mathrm{HCl}$ for EC and phosphate buffer (pH 6.8) for gelatin microspheres, respectively. From F6 batch, $50 \mathrm{mg}$ of microspheres were placed in glass vials containing $10 \mathrm{ml}$ of buffer and allowed to swell at $37 \pm 0.5^{\circ} \mathrm{C}$. The microspheres were periodically removed, blotted with filter paper, and their changes in weight were measured during the swelling until equilibrium was attained. Finally, the weight of the swollen microspheres was recorded using microbalance after $4 \mathrm{hrs}$ and swelling index was calculated using the formula,

$$
\mathrm{Wsi}=\frac{\mathrm{Wi}-\mathrm{Ws}}{\mathrm{Wi}}
$$

Where, Wsi=Swelling index of microspheres, Wi=Initial weight of the microspheres, and Ws=Final weight of the microspheres. The experiment was repeated in triplicate, and the average value was taken for the calculation.

f. Surface morphology by SEM [26]

Morphological characterization of the microsphere was done by taking SEM (JEOLJSM Model 5200, Japan). Cross-sectional view was obtained by cutting the microspheres with a razor blade. The samples for the SEM analysis were prepared by sprinkling the microspheres onto one side of the double adhesive stub, and the stub 
was then coated with gold using JEOL JFC 1100E sputter coater before microscopy. A working distance of $20 \mathrm{~nm}$, a tilt of $0^{\circ}$ and accelerating voltage of $15 \mathrm{Kv}$ were the operating parameters. The SEM photographs of the F6 LVD-microspheres were taken using JEOL-JEL-5300 scanning microscope.

Drug-polymer interaction studies

\section{FT-IR-radiation spectroscopy (FT-IR) [28,30]}

FT-IR (Shimadzu IR spectrophotometer, model 840, Japan) was used for the analysis in the frequency range between $4000 \mathrm{~cm}$ and $600 / \mathrm{cm}$, and $8 / \mathrm{cm}$ resolution and $0.2 / \mathrm{cm}$ rate. The results were the means of 16 determinations. A quantity equivalent to $2 \mathrm{mg}$ of the pure drug, empty microspheres, and drug-loaded microspheres were analyzed separately.

\section{Thermal analysis by DSC [28]}

DSC study of drug-loaded microcapsules was performed using a diamond DSC (Mettler Star SW 8.10) to determine the drug excipient compatibility. The analysis was performed at a rate $5^{\circ} \mathrm{C} / \mathrm{min}$ from temperature range between $50^{\circ} \mathrm{C}$ and $200^{\circ} \mathrm{C}$ under a nitrogen flow of $25 \mathrm{ml}$ minutes.

\section{In vitro drug release and kinetics study}

\section{In vitro drug release study [28,30]}

In vitro dissolution studies were performed using (USP Type II dissolution apparatus) rotating basket method specified in USP XXI at $100 \mathrm{rpm}$. The microspheres were weighed and tied in the muslin bag and placed in the basket. The dissolution medium used was $900 \mathrm{ml}$ of $0.1 \mathrm{M}$ hydrochloric acid for the first $2 \mathrm{hrs}$ and then changed to phosphate buffer $\mathrm{pH} 7.4$ from the $3^{\text {rd }} \mathrm{hrs}$. The temperature was maintained at $37^{\circ} \mathrm{C}$. An aliquot of $(5 \mathrm{ml})$ sample was withdrawn at specified time interval and replaced with an equivalent volume of dissolution fluid. Drug content was determined by a UV-VIS spectrophotometer (Shimadzu UV $1700 \mathrm{E} 23)$ at $267 \mathrm{~nm}$. The release studies were conducted in triplicate. Dissolution studies were performed for $24 \mathrm{hrs}$. Results were based on the triplicate determination.

\section{In vitro drug release kinetics [27,28,30]}

To study the exact mechanism of drug release from Microspheres, drug release data were analyzed according to zero order, first order, and Peppa's model. The criterion for selecting the most appropriate model was done on the basis of goodness of fit test. Data obtained from in vitro release study were fitted to various kinetic equations. To find out the mechanism of drug release, first $60 \%$ drug release was fitted in Peppa's equation. The kinetic models used were: Zero order equation: $(\mathrm{Q}=\mathrm{k} 0 \mathrm{t})$; First order equation: $\{\ln (100-\mathrm{Q})=\ln \mathrm{Q}-\mathrm{k} 1 \mathrm{t}\}$; Higuchi equation: $(\mathrm{Q}=\mathrm{kt1} / 2)$ Peppa's equation: $(\mathrm{Q}=\mathrm{kpt} \mathrm{n})$; where $\mathrm{Q}$ is the percent of the drug release at time $\mathrm{t}, \mathrm{k} 0$ and $\mathrm{kt}$ are the coefficients of the equations, and $n$ is the release exponent. The $n$ value was used to characterize different release mechanisms.

\section{Accelerated stability studies [26]}

Stability studies were performed on each set of formulations showing best performance with respect to in vitro release. Microspheres were stored at $4^{\circ} \mathrm{C}$, room temperature and $45^{\circ} \mathrm{C}$ for a month. In an interval 0 , 15,30 , and 45 days, samples were withdrawn and were assayed using the UV-VIS spectrophotometer at $267 \mathrm{~nm}$ using distilled water as blank. The experiment was repeated in triplicate, and the average value was taken for the calculation.

\section{RESULTS AND DISCUSSION}

The goal of any drug delivery system is to provide a therapeutic amount of drug at the proper site in the body and to maintain the desired drug concentration. Much of the research effort in developing novel drug delivery systems has been focused on multiple-unit dosage forms, such as microspheres for different reasons when compared to nondisintegrating single-unit dosage forms. The techniques employed to develop microparticles or microspheres have been investigated over the last two decades, but in fact, none of the encapsulation methodologies is ideal. Many researchers have altered and/or modified several of the encapsulation techniques to achieve specific goals and for it they should adopt an in-depth approach. Solvent evaporation technique is comparatively simple and has been applied for the encapsulation of a number of pharmaceuticals. There are numerous formulation and method specific considerations that may influence the characteristics of microspheres. The important pre-requisite for the successful use of microencapsulation technology involves the in-depth evaluation of the characteristics of microcapsules.

In this study, a total of nine formulations were prepared and characterized for various physical parameters to determine the optimal formulation. The solubility of lamivudine in $10 \mathrm{mg} / 10 \mathrm{ml}$ of solvent was carried out, and it revealed that it is soluble in water and methanol. The IR spectrum of lamivudine was found to be similar to the standard spectrum of lamivudine. The spectrum of lamivudine showed that the functional groups are present at their respective frequencies and is shown in Fig. 1. The melting point of lamivudine was found to be $180^{\circ} \mathrm{C}$. The standard calibration curve of lamivudine at $267 \mathrm{~nm}$ was performed.

The mean geometric particle size of LVD microspheres was found to be in the range of 34.61 to $51.45 \mu \mathrm{m}$ (Table 1). The best formulations were found to be F6, and its particle sizes were found to be $45.20 \mu \mathrm{m}$ (Fig. 1). The obtained microparticles slightly increase in their average particle size with increasing gelatin and glutaraldehyde ratio. Glutaraldehyde cross-linking increases the viscosity of gelatin solution.

The average particle size range of $\mathrm{F} 6$ formulation was found to be $45.2 \mu \mathrm{m}$.

The surface morphology of the LVD microspheres was studied by SEM SEM photographs of blank and F6 microspheres were shown in Figs. 3 and 4. It showed that glutaraldehyde cross-linking and gelatin enhance the spherical shape and smooth surface of the lamivudine microspheres. The difference in the surface of the drug-loaded microspheres from the blank manifested the presence of drug particles. All the microspheres had small pores on their surfaces, which will be responsible for the release.

Table 1: Particle size, swelling index, \% yield, \% drug content, and entrapment efficiency

\begin{tabular}{|c|c|c|c|c|c|c|}
\hline S. No. & $\begin{array}{l}\text { Formulation } \\
\text { code }\end{array}$ & $\begin{array}{l}\text { Particle } \\
\text { size }(\mu \mathrm{m})\end{array}$ & $\begin{array}{l}\text { Swelling } \\
\text { index }\end{array}$ & $\begin{array}{l}\text { Percentage } \\
\text { yield }\end{array}$ & $\begin{array}{l}\text { Drug } \\
\text { content (\%) }\end{array}$ & $\begin{array}{l}\text { Entrapment } \\
\text { efficiency (\%) }\end{array}$ \\
\hline 1 & F1 & $34.61 \pm 0.29$ & $2.84 \pm 0.37$ & $81.01 \pm 1.52$ & $99.54 \pm 0.81$ & $55.13 \pm 3.12$ \\
\hline 2 & F2 & $37.45 \pm 0.46$ & $2.45 \pm 0.62$ & $84.52 \pm 0.98$ & $98.61 \pm 1.15$ & $56.57 \pm 1.35$ \\
\hline 3 & F3 & $39.56 \pm 0.35$ & $2.32 \pm 0.25$ & $86.43 \pm 2.43$ & $98.32 \pm 0.97$ & $58.11 \pm 0.97$ \\
\hline 4 & F4 & $41.63 \pm 0.87$ & $2.93 \pm 0.55$ & $75.64 \pm 1.35$ & $97.35 \pm 1.69$ & $61.92 \pm 2.61$ \\
\hline 5 & F5 & $44.35 \pm 0.56$ & $3.05 \pm 0.86$ & $77.45 \pm 2.21$ & $96.53 \pm 0.85$ & $63.83 \pm 1.12$ \\
\hline 6 & F6 & $45.20 \pm 0.39$ & $3.14 \pm 0.47$ & $79.31 \pm 0.96$ & $96.25 \pm 1.53$ & $65.55 \pm 0.93$ \\
\hline 7 & F7 & $48.38 \pm 0.22$ & $3.93 \pm 0.39$ & $71.55 \pm 1.61$ & $95.64 \pm 0.61$ & $66.75 \pm 2.91$ \\
\hline 8 & F8 & $49.41 \pm 0.73$ & $3.57 \pm 0.53$ & $73.61 \pm 1.22$ & $94.55 \pm 1.47$ & $67.83 \pm 1.47$ \\
\hline 9 & F9 & $51.45 \pm 0.45$ & $3.23 \pm 0.66$ & $74.82 \pm 1.18$ & $94.31 \pm 0.89$ & $69.61 \pm 0.99$ \\
\hline
\end{tabular}




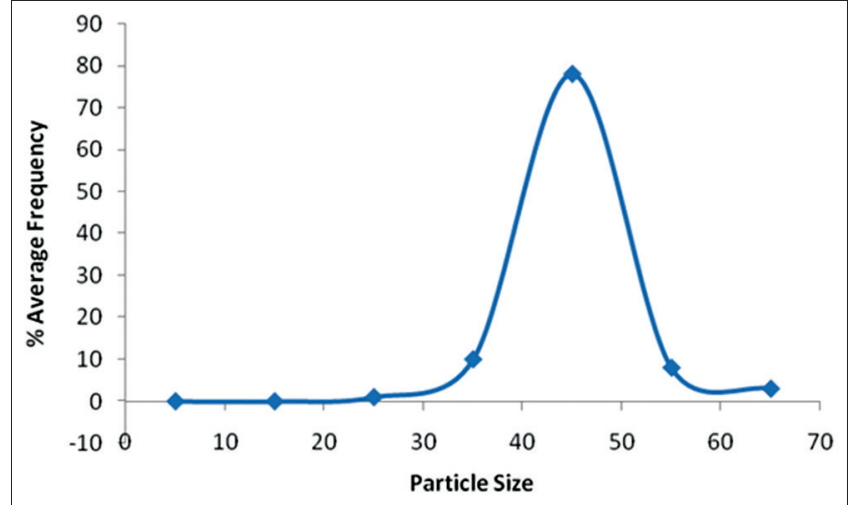

Fig. 1: Particle size frequency distribution profile of the optimized formulation $\mathrm{F} 6$

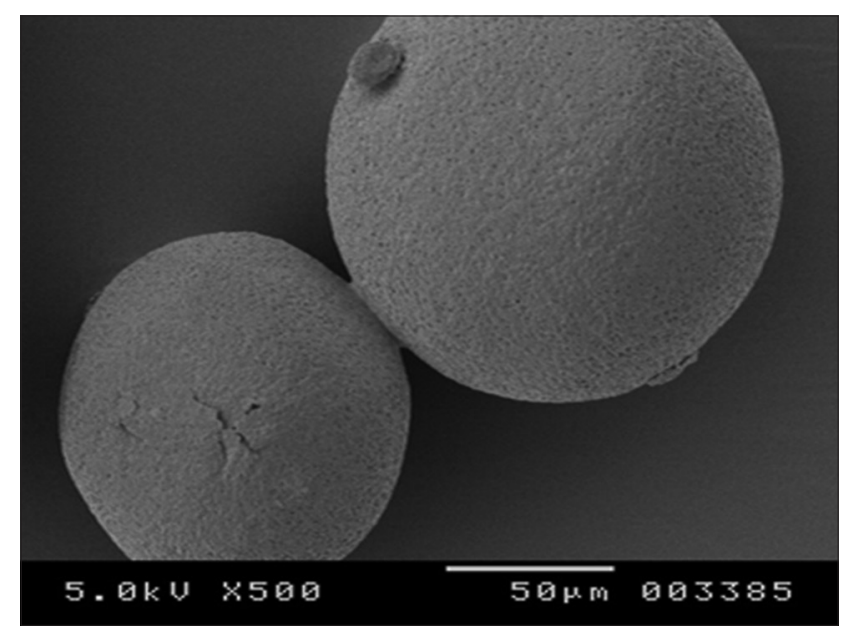

Fig. 2: Surface morphology of blank microspheres

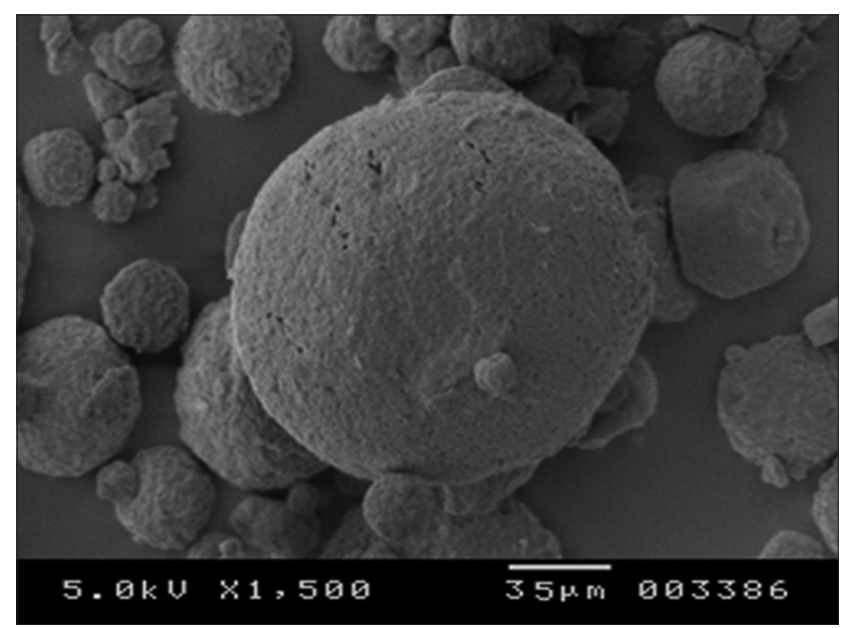

Fig. 3: Surface morphology of gelatin-liver venous deprivation microspheres (F6)

The percentage yield for all the formulations was found to be in the range between $71.55 \%$ and $86.43 \%$ and the maximum yield of $86.43 \%$ was observed with F3. The percentage of drug content in the formulations was found to be in the range of 94.31-99.54\%. The percentage drug entrapment was found to be 55.13-69.61\%. It was evident from the results that F9 possessed the highest DEE of $69.61 \%$. It was further observed that the DEE was proportional to the drug: Polymer ratio and also to the size of the LVD microspheres. For gelatin LVD microspheres, it was found that agitation speed and glutaraldehyde concentration had no effect on drug content, whereas polymer to drug concentration attributes to the drug content of the formulation. The results obtained were shown in Table 1.

The swelling index values of LVD microspheres were found to be in the range of 2.32-3.93. In swelling studies, it was observed that swellability increases with increase in the gelatin ratio and cross-linking did not affect the swelling percentage of microspheres.

The FT-IR spectrum was obtained for LVD powder, gelatin, and physical mixture of LVD and polymer (F6), which are shown in Figs. 1, 5 and 6. The characteristic peaks of the LVD were compared with the peaks obtained for physical mixture of LVD and polymer. The characteristic peaks found in LVD and formulations proved that there was no chemical interaction between LVD and polymer. It has two distinct absorption bands: the $\mathrm{C}=0$ stretching at $1633 / \mathrm{cm}$ and $\mathrm{N}-\mathrm{H}$ stretching at $3407 / \mathrm{cm}$. The characteristic absorptions of the backbone occurring at 1510 and $1638 / \mathrm{cm}$ are the only distinguishing features of gelatin. The cross-linked gelatin microspheres show, in addition to the previously mentioned peaks, the aldimine adsorption peak at $1458 / \mathrm{cm}$. FT-IR studies revealed that the drug and gelatin were satisfactorily compatible, without any significant changes in the chemical nature of the drug.

The DSC results (Figs. 7 and 8) demonstrated a sharp endothermic peak for LVD at $179-180^{\circ} \mathrm{C}(\mathrm{F} 6)$, which corresponds to its melting point. The melting point reported for LVD was $180^{\circ} \mathrm{C}$ indicating the crystalline nature of the drug. From DSC, the physical mixture of LVD and polymer and the pure drug showed the same thermal behavior $180^{\circ} \mathrm{C}$ as the individual component, indicating that there was no interaction between the LVD and polymer in the solid state.

The in vitro release performance of LVD microspheres showed the prolonged and controlled release of the drug. The F6 released $7.42 \%$ of the drug at the end of $1 \mathrm{~h}$ and steadily released the drug up to $93.23 \%$ at the end of $24 \mathrm{hrs}$. The results of in vitro release data of lamivudine microspheres are shown in Fig. 9.

The drug release profiles of gelatin microparticles as a function of glutaraldehyde ratio. The cross-linked gelatin microparticle showed a decrease in drug release over a long period. The mechanism of drug release was based on swelling-controlled and erosion-controlled strategies. The initial release of the drug model mainly dependents on surface erosion or dissolution of the microparticle matrix. The glutaraldehyde cross-linking can decrease the drug release, and it is because of the cross-linked structure of the gelatin matrix inhibiting the drug release, i.e., increasing glutaraldehyde ratio and decreasing gelatin ratio.

The drug release levels for F1, F2, F3, F4, F5, F6, F7, F8, and F9 at $24 \mathrm{hrs}$ were $85.82,87.42,89.92,89.22,91.52,93.23,71.51,73.32$, and $75.33 \%$, respectively. The level of drug release steadily increased as the gelatin ratio increased but becomes slower at low gelatin concentrations. The release becomes slower at a higher amount of glutaraldehyde but becomes faster at low glutaraldehyde concentrations. In this study, F6 showed a better-sustained release level compared to the other formulations.

The basic concept in the design of controlled release drug delivery is that the availability of drug depends on the kinetics of the drug release rather than drug absorption. The release mechanisms of LVDgelatin microspheres from various formulations were determined by comparing their correlation coefficient.

The release of drug for all formulations was observed to predominantly follow zero order release pattern. The release pattern mainly depends on the type of polymer and viscosity. The coefficient of determination indicated that the release data of F6 was best fitted with zero order kinetics. The drug release from F6 follows zero order kinetics $\left(\mathrm{r}^{2}=0.989\right)$ 


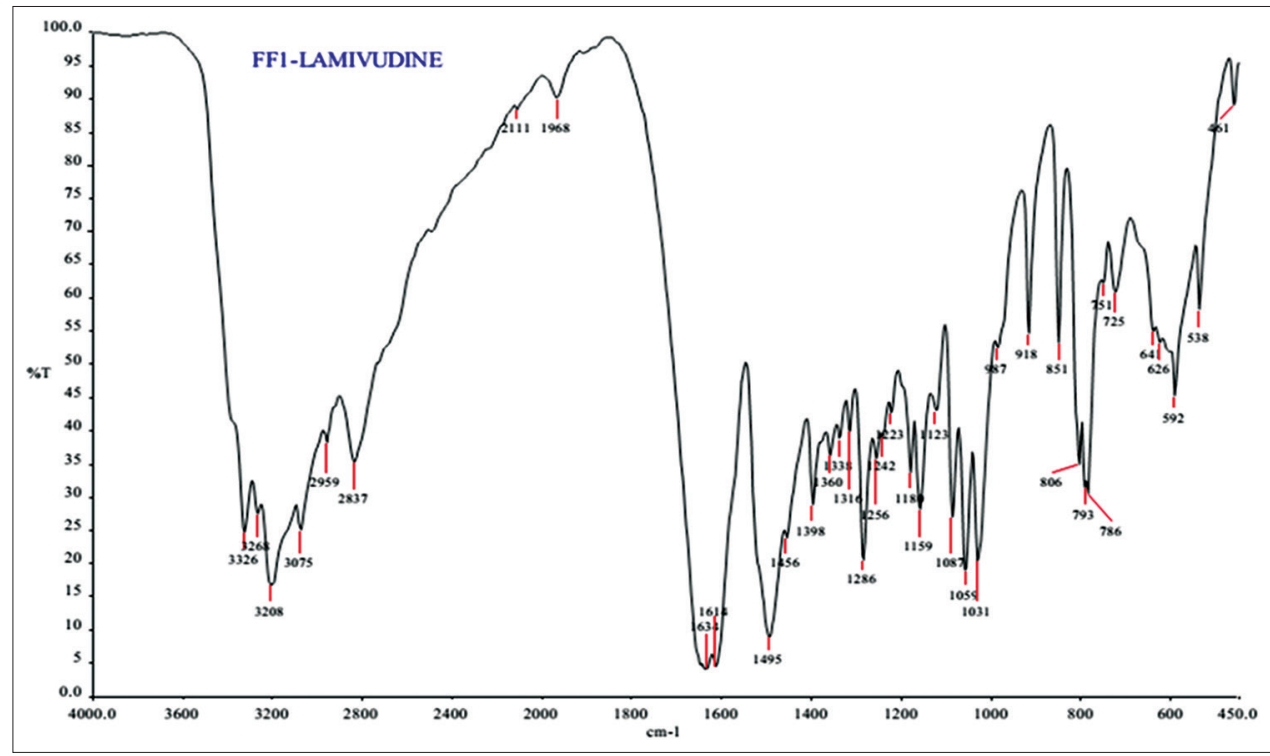

Fig. 4: Fourier transform-infrared of lamivudine

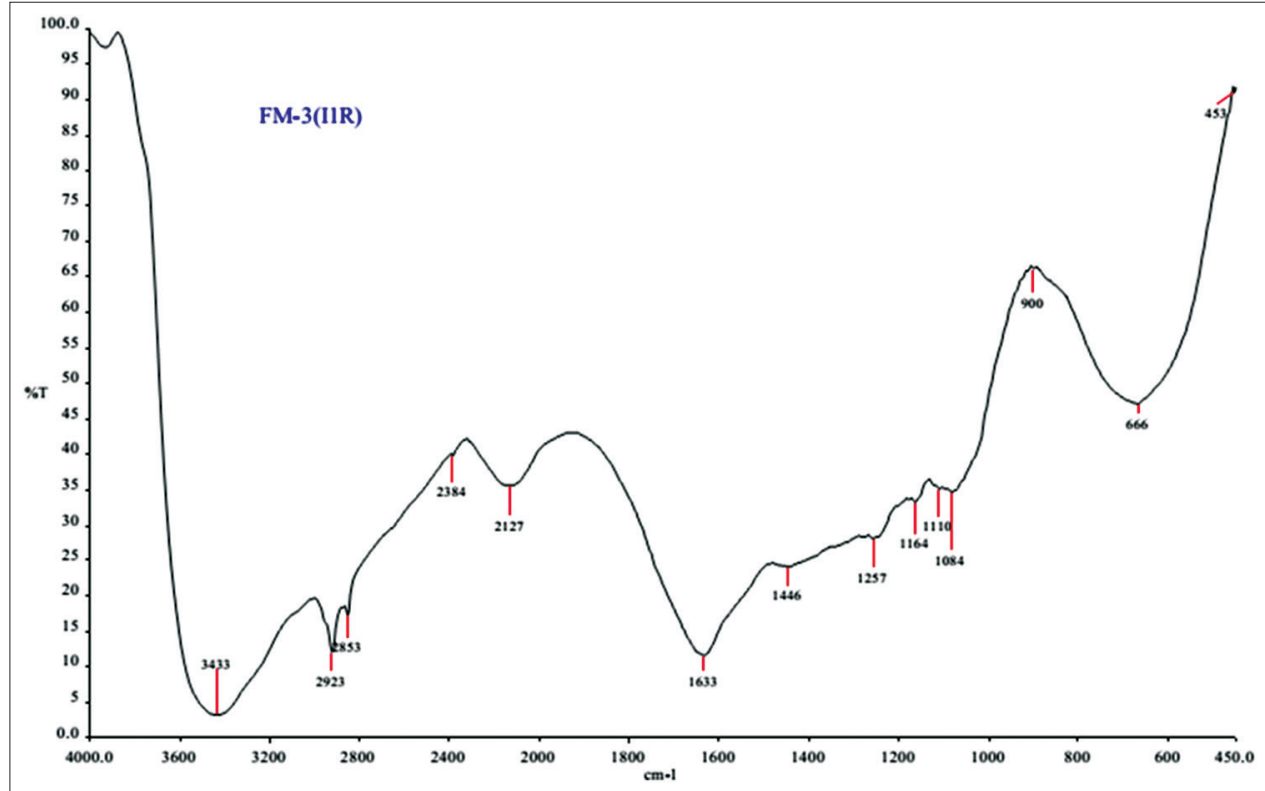

Fig. 5: Fourier transform-infrared of gelatin

with release component value of $n=0.888$ (Peppa's), indicating NonFickian diffusion type release (Table 2).

The formulation F6 showing the best performance with respect to in vitro release were stored at $4^{\circ} \mathrm{C}, 37^{\circ} \mathrm{C}$, and $45^{\circ} \mathrm{C}$ for a month for accelerated stability studies, and the results obtained were shown in Fig. 10. The results of stability studies showed that there is about $90.19 \%$ of drug release for $\mathrm{F} 6$ after storage at $45^{\circ} \mathrm{C}$ for 45 days. This indicates the broader horizon of storage conditions and good stability of microspheres.

On the basis of release data and graphical analysis formulation F6 showed a good controlled release profile with maximum entrapment efficiency. By comparing with the previous reports of LVD-ethyl cellulose microspheres (Ghosh et al., 2007), LVD-gum microspheres (Shankar et al., 2008), LVD floating hollow microspheres (Vishnupriya et al.,2012), there was somewhat effective controlled release observed in this investigation. It is evident that promising controlled release microspheres can be developed by ionic gelation techniques using
Table 2: Regression coefficient $\left(r^{2}\right)$ values of different kinetic models and diffusion exponent (n) of Peppa's model for lamivudine microspheres

\begin{tabular}{lllll}
\hline Formulation & $\begin{array}{l}\text { Zero } \\
\text { order }\end{array}$ & $\begin{array}{l}\text { First } \\
\text { order }\end{array}$ & $\begin{array}{l}\text { Higuchi } \\
\text { matrix }\end{array}$ & $\begin{array}{l}\text { Peppa's } \\
\text { plot }\end{array}$ \\
\hline F1 & 0.973 & 0.984 & 0.942 & 0.83 \\
F2 & 0.983 & 0.974 & 0.954 & 0.818 \\
F3 & 0.984 & 0.970 & 0.945 & 0.841 \\
F4 & 0.994 & 0.93 & 0.915 & 0.861 \\
F5 & 0.994 & 0.869 & 0.897 & 0.869 \\
F6 & 0.989 & 0.917 & 0.899 & 0.888 \\
F7 & 0.993 & 0.981 & 0.935 & 0.866 \\
F8 & 0.983 & 0.988 & 0.963 & 0.796 \\
F9 & 0.995 & 0.949 & 0.898 & 0.913 \\
\hline
\end{tabular}

gelatin, glutaraldehyde, and span 80 . This preliminary study should be continued further to study the influence of polymer concentration 


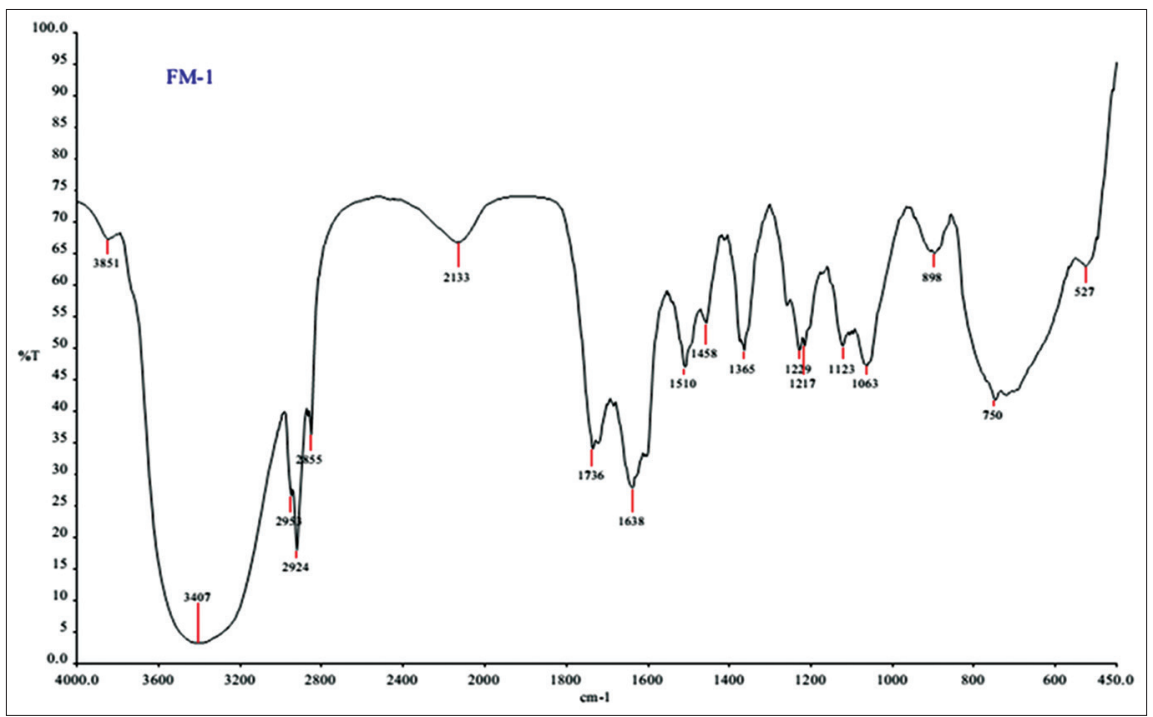

Fig. 6: Fourier transform-infrared of F6 (lamivudine, gelatin, and glutaraldehyde; 1:2:6)

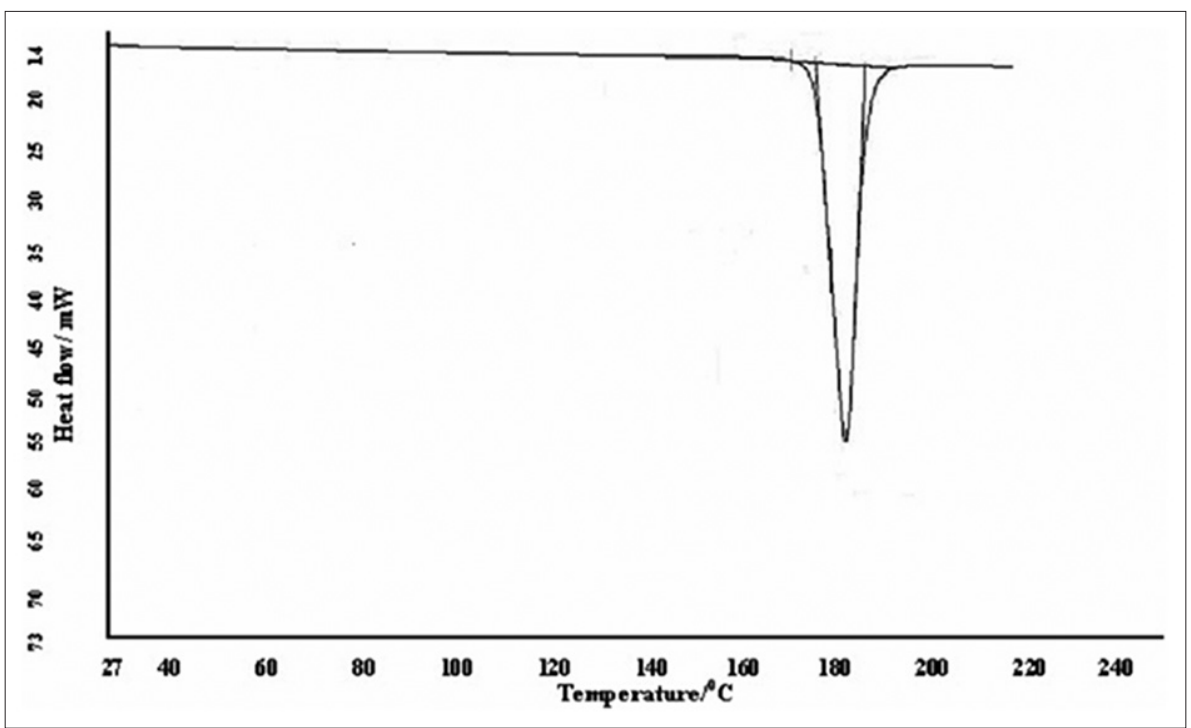

Fig. 7: Differential scanning calorimetry thermogram of pure lamivudine drug

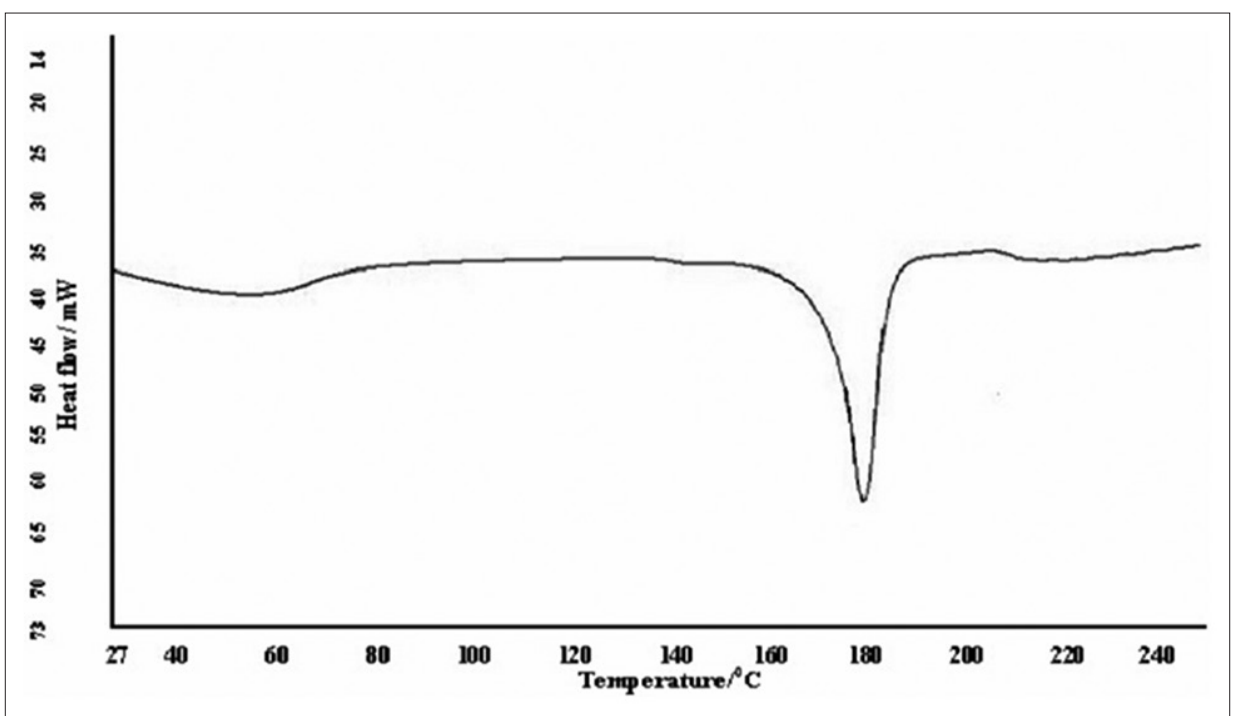

Fig. 8: Differential scanning calorimetry thermogram of F6 (lamivudine, gelatin, and glutaraldehyde; 1:2:6) 


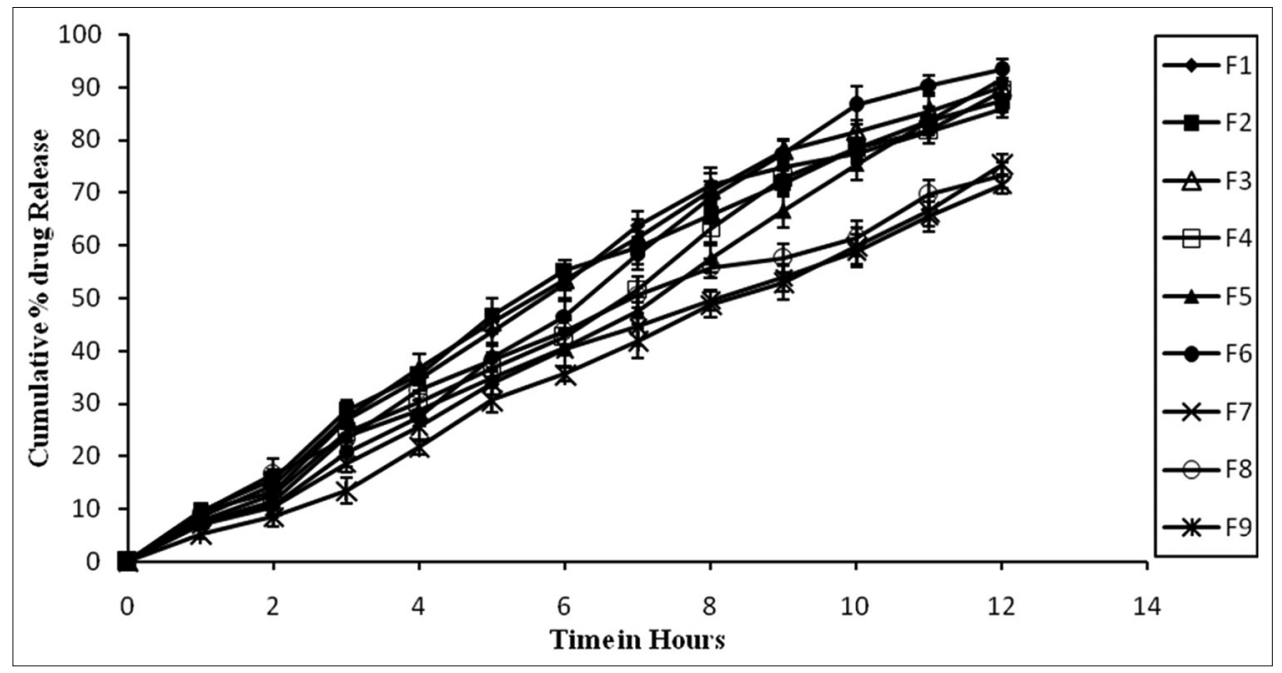

Fig. 9: Comparative in vitro release profile of liver venous deprivation microspheres

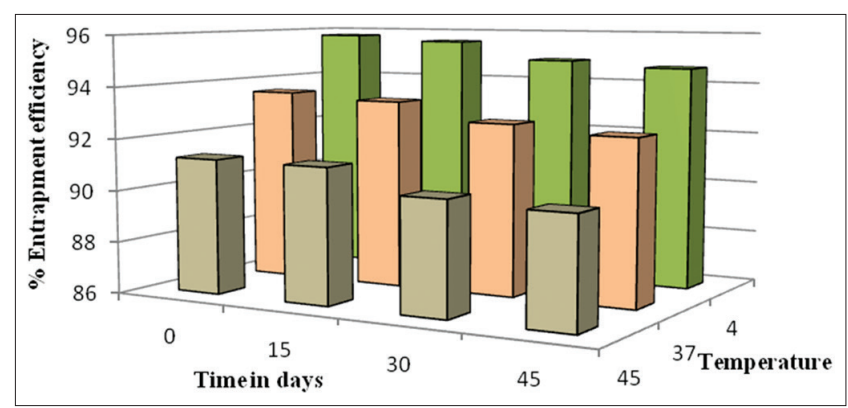

Fig. 10: Accelerated stability studies for F6

and exploration of other cross-linking agents and surfactants. The optimization of drug release to develop an effective delivery system could be investigated on animal models for progressive exploration in the future.

\section{CONCLUSIONS}

In our study, a satisfactory attempt was made to develop a formulation with improved bioavailability and patient compliance, efficient dose reduction, and targeting capacity. The findings of our investigation demonstrated that F6 of gelatin-LVD microspheres had good controlled release profile with maximum entrapment efficiency and prolonged drug release for $24 \mathrm{hrs}$ or longer, and this formulation would be capable of overcoming the drawbacks and limitations of lamivudine conventional dosage forms.

In context to the intense worldwide research to combat AIDS, it can be envisaged that future works would indulge in the optimization of the selected formulation (F6), to promote its commercial scale up lamivudine microspheres for effective management of AIDS. Furthermore, in near future by combining various other strategies, microspheres will find the central place in novel drug delivery, particularly in diseased cell sorting, diagnostics, gene and genetic materials, safe, targeted and effective in-vivo delivery, and supplements as miniature versions of diseased organ and tissues in the body.

\section{REFERENCES}

1. Prakash K, Raju PN, Shanta KK, Lakshmi MN. Preparation and characterization of lamivudine microcapsules using various cellulose polymers. Trop J Pharm Res 2007;6(4):841-7.

2. Perry CM, Faulds D. Lamivudine-A review of its antiviral activity, pharmacokinetic properties and therapeutic efficacy in the management of HIV infection. Drugs 1997;53(4):667-80.
3. Over M, Heywood P, Gold J, Gupta I, Hira S, Marseille E. Treatment and Prevention in India Modeling the Cost and Consequences. Washington, D.C: The International Bank for Reconstruction and Development/The World Bank; 2004. p. 14.

4. Pradeep B, Nagamadhu M, Banji D, Madhavi BB, Arjun G, Shekhar K. Formulation and evaluation of valaciclovir hydrochloride microcapsules. Int J Pharm Pharm Sci 2011;3(2):92-6.

5. Merrill DP, Moonis M, Chou TC, Hirsch MS. Lamivudine or stavudine in two- and three-drug combinations against human immunodeficiency virus Type 1 replication in vitro. J Infect Dis 1996;173(2):355-64.

6. Furman PA, Fyfe JA, St Clair MH, Weinhold K, Rideout JL, Freeman GA, et al. Phosphorylation of 3'-azido-3'-eoxythymidine and selective interaction of the $5^{\prime}$-riphosphate with human immunodeficiency virus reverse transcriptase. Proc Natl Acad Sci U S A 1986;83(21):8333-7.

7. Amitava G, Udaya Kumar N, Partha R. Development, evaluation and method selection for the preparation of lamivudine microspheres. Int J Pharm Pharm First Published June; 2007. Available from: http://www. priory.com

8. Ghosh A, Nayak UK, Roy P. Development, evaluation and method selection for the preparation of lamivudine microspheres. Int J Pharm 2007;9:67-71.

9. Zhang C, Cheng Y, Qu G, Wu X, Ding Y, Cheng Z, et al. Preparation and characterization of galactosylated chitosan coated BSA microspheres containing 5-fluorouracil. Carbohydr Polym 2008;72(3):390-7.

10. Gibaldi M. Controlled drug delivery systems. In: Biopharmaceutics and Clinical Pharmacokinetics. $3^{\text {rd }}$ ed. Philadelphia, PA: Lea and Febiger; 1987. p. 129-85.

11. Chien YW. Controlled and modulated release drug delivery systems. In: Swarbrick J, Boylan JC, editors. Encyclopedia of Pharmaceutical Technology. New York: Marcel Dekker Inc.; 1990. p. 280-5.

12. Dhanaraju MD, Kumar RM, Nithya P, Kishan JV, Thirumurugan G Controlled delivery of antiretroviral drug loaded chitosan cross-linked microspheres. Arch Appl Sci Res 2009;1(2):279-86.

13. Parvathi M, Prathyusha A, Kiran RS, Reddy RJ. Preparation and evaluation of quetiapine fumarate microemulsions: A novel delivery system. Asian J Pharm Clin Res 2014;7(2):208-13.

14. Kavitha K, Pavanveena C, Anil Kumar SN, Tamizh Mani T. Formulation and evaluation of trimetazidine hydrochloride loaded gelatin microspheres. Int J Pharm Pharm Sci 2010;3(2):67-70.

15. Joshi JR, Patel RP. Role of biodegradable polymers in drug delivery. Int J Curr Pharm Res 2012;4(4):74-81.

16. Arunachalam A, Rathinaraj BS, Subramanian, Choudhury PK, Reddy KA, Fareedullah MD. Preparation and evaluation of ofloxacin microspheres using natural gelatin polymer. Int J Appl Biol Pharm Technol 2010;1(1):61-7.

17. Pérez-Rodriguez C, Montano N, Gonzalez K, Griebenow $\mathrm{K}$. Stabilization of $\alpha$-chymotrypsin at the $\mathrm{CH}_{2} \mathrm{Cl}_{2}$ /water interface and upon water-in-oil-in-water encapsulation in PLGA microspheres. J Control Release 2003;89(1):71-85.

18. Althaf AS, Seshadri T. Design and study of lamivudine oral sustained release tablets, Pelagia research library. Der Pharm Sin 2010;1(2):61-76.

19. Chavda Y, Bhimani B, Patel U, Shah R, Patel G, Daslaniya D. 
Preparation and evaluation of lamivudine microspheres with Eudragit $\AA$ polymers by solvent evaporation method For lymphatic system. Int J Pharm Res Biosci 2003;2(3):89-106.

20. Dey S, Roy N, Mazumdar B. Effect of formulation and process variables on the characteristics of microspheres of antiviral drug (stavudine) prepared by oil-in-oil solvent evaporation technique. Int $\mathrm{J}$ Pharm Pharm Sci 2010;2(2):52-9.13. Gibaud S, Bonneville A, Astier A. Preparation of 3, 4-diaminopyridine microparticles by solvent-evaporation methods. Int J Pharm 2002;242(1-2):197-201.

21. Josephine LJ, Madhusudhan NT, Wilson B, Manjula D, Savitha BK Formulation and characterization of ritonavir loaded ethyl cellulose microspheres for oral delivery. World J Pharm Res 2012;1(2):207-15.

22. Jayan SC, Sandeep AV, Rifas M, Mareema CM, Shamseera S. Design and in-vitro evaluation of gelatin microspheres of salbutamol sulphate. Hygeia J D Med 2009;1(1):17-20.

23. Karthikeyan K, Durgadevi R, Saravanan K, Shivsankar K, Usha S, Saravanan M. Formulation of bioadhesive carbomer gel incorporating drug-loaded gelatin microspheres for periodontal therapy. Trop J Pharm Res 2012;11(3):335-43

24. Nath B, Nath LK, Kumar P. Preparation and in vitro dissolution profile of zidovudine loaded microspheres made of Eudragit RS100, RL100 and their combinations. Acta Pol Pharm Drug Res 2011;68(3):409-15.

25. Pradeep B, Nagamadhu M. Formulation and evaluation of valaciclovir hydrochloride microcapsules. Int J Pharm Pharm Sci 2011;3(2):92-6.

26. Shankar NB, Kumar NU. Lamivudine loaded microspheres for oral use: Design, development and establishment of in vivo-in vitro correlation. Asian J Pharm Clin Res 2009;2(1):55-60.

27. Pandit V, Pai RS, Yadav V, Devi K, Surekha BB, Inamdar MN, et al. Pharmacokinetic and pharmacodynamic evaluation of floating microspheres of metformin hydrochloride. Drug Dev Ind Pharm 2013;39(1):117-27

28. Rao RN, Prakash K. Preparation and evaluation of lamivudine microspheres using various cellulose polymers. Int $\mathrm{J}$ Pharm Tech 2011;3(1):1397-410.

29. Ikam VK, Gudsoorkar VR, Dolas RT, Somwanshi SB, Gaware VM, Kotade KB, et al. Microspheres: A novel drug delivery system an overview. Pharmacologyonline 2011;3:352-75.

30. Pavanveena C, Kavitha K, Anil Kumar SN. Formulation and evaluation of trimetazidine hydrochloride loaded chitosan microspheres. Int J Appl Pharm 2010;2(2):11-4. 